\title{
Design and experiment on scion cutting mechanism of grafting robot for cucurbit
}

\author{
Liping Chen ${ }^{1}$, Kai Jiang ${ }^{1 *}$, Qian Zhang ${ }^{2}$, Wenzhong Guo ${ }^{1}$, Wengang Zheng ${ }^{1}$ \\ (1. Beijing Research Center of Intelligent Equipment for Agriculture, Beijing 100097, China; \\ 2. Beijing Research Center of Information Technology for Agriculture, Beijing 100097, China)
}

\begin{abstract}
The scion cutting mechanism of the traditional grafting machine cannot correct the bending degree of the scion seedling stem so that the cutting angle of the scion seedling is not standard and the survival rate of the grafted seedling is affected. In this study, cucumber seedlings and watermelon seedlings were taken as experimental objects. Based on the analysis of the geometric parameters and mechanical characteristics of scion seedlings, a scion cutting mechanism with holding seedling applied to cucumber seedlings and watermelon was designed and developed. The main structure and operating parameters of $\mathrm{V}$-shaped holding seedling block and cutting unit were determined, and holding seedling and cutting performance tests were carried out. The test results showed that compared with the common arc clamp, the V-shaped holding seedling block had a better guiding and centering effect on the scion seedling, could better correct the bending state of the scion seedling stem, and the success rate of holding seedling of the V-shaped holding block reached $98.33 \%$, which was increased by $13.33 \%$ compared with the arc-shaped clamp, and the seedling injury rate was only $1.67 \%$. The upper and lower two-point positioning of scion stem by clamping hand and holding seedling block can improve the cutting performance effectively. The cutting accuracy rate of the scion was $97.75 \%$, and the cutting success rate was $98.67 \%$. The cutting performance was closely related to the holding seedling effect. The research results can provide a reference for the design of cutting mechanisms of melon grafting robots.
\end{abstract}

Keywords: grafting robot, cutting mechanism, holding seedling block, scion seedlings, cucurbit

DOI: $10.25165 /$ j.ijabe.20201305.5810

Citation: Chen L P, Jiang K, Zhang Q, Guo W Z, Zheng W G. Design and experiment on scion cutting mechanism of grafting robot for cucurbit. Int J Agric \& Biol Eng, 2020; 13(5): 99-106.

\section{Introduction}

The vegetable grafting technology can effectively overcome the soil continuous cropping obstacle and diseases and insect pests, improve the resistance of crops, reduce the application of pesticides and chemical fertilizers, increase crop yield by $20 \%-50 \%{ }^{[1-3]}$. As a result, this technology is widely used in the world ${ }^{[4,5]}$. The splice grafting method has good universality and a high survival rate. Melon grafting machine mostly adopts the splice grafting method, because the scion seedling stem is relatively small and tender, and the seedling stem is curved, which increases the difficulty of cutting operation ${ }^{[6-8]}$.

China $^{[9-12]}$, Japan ${ }^{[13-15]}$, Korea ${ }^{[16,17]}$, Holland ${ }^{[18,19]}$ and other countries ${ }^{[20-23]}$ have been developed different types of grafting machine products. Due to the lack of adaptive research on seedlings, the application of grafting machine is limited. In the GRF800-U automatic grafting machine developed by Kobayashi

Received date: 2020-03-29 Accepted date: 2020-07-31

Biographies: Liping Chen, $\mathrm{PhD}$, Researcher, research interest: precision agriculture, Email: chenlp@nercita.org.cn; Qian Zhang, Master, Research Assistant, research interest: agricultural informatization, Email: zhangq@nercita.org.cn; Wenzhong Guo, PhD, Researcher, research interest: facility gardening equipment, Email: guowz@nercita.org.cn; Wengang Zheng, $\mathrm{PhD}$, Researcher, research interest: agricultural informatization and automatic control, Email: zhengwg@ nercita.org.cn.

*Corresponding author: Kai Jiang, PhD, Senior Engineer, research interest: agricultural intelligent equipment and agricultural robot. Beijing Research Center of Intelligent Equipment for Agriculture, Beijing 100097, China. Tel: +86-18500356086, Email: jiangk@nercita.org.cn. and Sasaya ${ }^{[14]}$, a linear cutting mechanism was designed. Due to the lack of straightening operation for the seedling stem, the cutting quality is greatly affected by seedling morphology ${ }^{[24,25]}$. In the AFGR-800CS grafting machine developed by Kang et al., a rotary cutting mechanism was designed, and the formed arc section affected the docking tightness of grafting seedlings ${ }^{[26]}$. In a cutting tool holder designed by Zhang et al. ${ }^{[27,28]}$, the cutting success rate was low because of the complexity of cutting angle adjustment. ISO group company of the Netherlands developed a kind of rootstock and scion synchronous linear cutting mechanism, which could ensure the consistency of cutting angle and had high requirements for seedling stem matching grafting ${ }^{[29]}$. Jiang et al. ${ }^{[30,31]}$ developed the rotary cutting mechanism. They used the top seedling plate and supporting rod to assist the cutting operation, but did not solve the influence of the bending of seedling stem on the cutting quality. Wu et al. ${ }^{[32,33]}$ developed a visual recognition system for the external shape parameters of the seedling for grafting, which provided informed guidance for cutting mechanism operation. To sum up, the existing cutting mechanism of the melon grafting machine is lack of straightening operation for seedling stem, and the influence of scion seedling stem bending on cutting accuracy is not solved. The arc section of the seedlings completed by the rotary cutting mechanism affects the survival rate of the grafted seedlings. The straight cutting mechanism can ensure that the grafted seedlings are closely connected with each other and improve the survival rate of the grafted seedlings.

In order to solve the problem of low cutting precision of scion 
in the existing grafting machine, a scion cutting mechanism with the function of holding and positioning seedlings was developed in this paper, which combined the two-point clamping positioning of the seedling stem with linear cutting to realize high-quality cutting of scion seedlings. In this paper, the V-shaped holding seedling block and linear cutting unit were designed, the operation parameters of the holding seedling block and cutting unit were analyzed and determined, and the holding and cutting seedling experiments were carried out. The research results can provide a reference for the design of cutting mechanisms of grafting robots.

\section{Materials and methods}

\subsection{Overall structure of grafting robot}

The overall structural design of the vegetable grafting robot is shown in Figure 1. In order to achieve high-speed grafting, the rootstock and scion clamping and conveying mechanism are respectively provided with 4 holding hands. On the left and right sides of the operation, platforms were set as the seedling loading station and used to install the rootstock and scion seedling feeding platform; the $90^{\circ}$ clockwise rotation of the rootstock clamping and conveying mechanism was set as the rootstock cutting station; The $90^{\circ}$ counterclockwise rotation of the scion clamping and conveying mechanism was set as the scion cutting station; the central position between the seedling loading station of the rootstock and scion was set as the docking station, and the relative positions of the cutting station of the rootstock and scion were set as empty. The above layout realizes the synchronous operation of three stations for seedling loading, cutting and docking. For each $90^{\circ}$ rotation of the rootstock and scion clamping and conveying mechanism, a grafted seedling can be completed, which improves the productivity of grafting ${ }^{[34]}$.

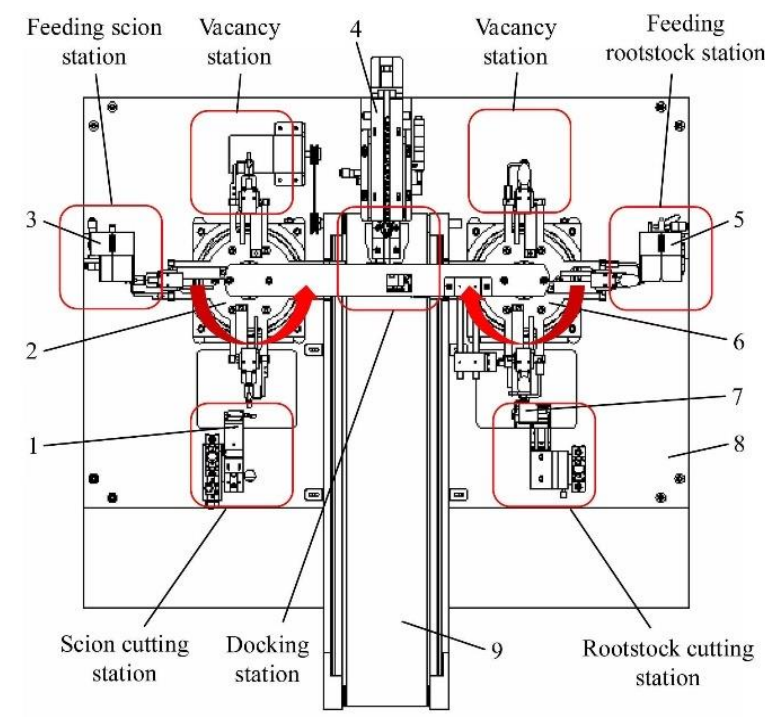

1. Scion cutting mechanism 2. Scion clamping and carrying mechanism 3. Scion supply platform 4. Automatic feeding clamp mechanism 5. Rootstock supply platform 6 . Rootstock clamping and carrying mechanism 7. Rootstock cutting mechanism 8. Operation platform 9. Conveyor belt

Figure 1 Structure diagram of grafting robot

Workflow: (1) Put the rootstock and scion into their seedling feeding platform, and adjust the cotyledon direction and the height of the seedling; (2) Take out the rootstock seedling by the rootstock clamping and conveying mechanism and rotate it $90^{\circ}$ clockwise to the rootstock cutting station, and cut a piece of cotyledon and growth point by the rootstock cutting mechanism; Meanwhile, take out the scion seedling by the scion clamping and conveying mechanism and rotate it $90^{\circ}$ counterclockwise to the scion cutting station. The scion cutting mechanism gathers and cuts off the scion seedlings; (3) The rootstock and scion clamping and conveying mechanisms continue to rotate $90^{\circ}$ to the docking station, respectively. After the cutting and docking of the rootstock and scion, the automatic upper clamping mechanism discharges a grafting clamp to complete the cutting fixation of the rootstock and scion. (4) The holding hands of the rootstock and scion are opened at the same time, and then the grafting seedling is released and landed on the conveyor belt to complete a grafting cycle.

\subsection{Design of scion cutting mechanism}

\subsubsection{Structure and working principle}

The role of the scion cutting mechanism is to position and cut the scion seedlings to ensure that the scion seedlings are upright during the cutting process, otherwise, the cutting position of the scion will deviate and the cutting angle will be too large or too small. The scion cutting mechanism is shown in Figure 2. The cutting unit 4 is fixed on the holding seedling unit 3 through the connection block 5 , and the holding seedling unit 3 is fixed on the moving unit 7 through the connection plate 6 . The clamping hand 1 and the holding seedling unit 3 are fixed to form the upper and lower two-point on the stem of the scion seedling. The cutting direction of the cutting unit 4 is perpendicular to the clamping direction of the clamping hand 1 .

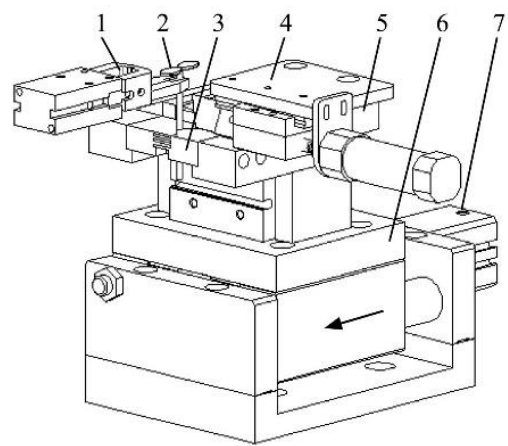

1. Clamping hand 2. Scion seedling 3. Holding seedling unit 4. Cutting unit 5. Connecting block 6. Connecting plate 7. Moving unit

Figure 2 Structure diagram of scion cutting mechanism

Working process: First, clamping hand 1 carry the scion seedling 2 to the cutting station. The moving unit 7 is extended to transport the holding seedling unit 3 and the cutting unit 4 to the holding seedling position; the holding seedling unit 3 straightens and positions the scion seedling 2 ; the cutter of the cutting unit 4 is extended to complete the cutting operation of the scion seedling 2 ; the holding seedling unit 3 , the cutting unit 4 and the moving unit 7 are sequentially reset to complete a cutting operation.

\subsubsection{Design of holding seedling unit}

The holding seedling unit consists of the clamping finger, the holding seedling block and the air cylinder, as shown in Figure 3a. The holding seedling block was designed as a V-shaped multilayer concave and convex structure with V-shaped holding seedling mouth and holding seedling center, as shown in Figure $3 \mathrm{~b}$. The center of the holding seedling is arc-shaped. After the left and right holding seedling blocks are closed, an oval holding seedling space is formed to ensure the safety of the holding of the scion seedlings. A clamping pad was arranged at the lower part of the holding seedling block for clamping and fixing the stem of scion seedling. 
The stem of scion seedling is curved under the natural condition, which affects the cutting quality, as shown in Figure 4a. Through the relative closing movement of the left and right holding seedling blocks, the V-shaped holding seedling mouth is cross-closed. The friction between the edge of the $\mathrm{V}$-shaped holding seedling mouth and the seedling stem causes the scion to move toward the center of the holding seedling, and the $\mathrm{V}$-shaped holding seedling mouth of the holding seedling block has a guiding and centering effect on the scion seedlings to ensure that the scion seedling to reach the center of the holding seedling smoothly, thereby correcting the bending shape of the scion seedlings and ensuring the accuracy of the scion cutting. The holding seedling operation and the size of the holding seedling block are shown in Figure $4 \mathrm{~b}$. The overall dimensions of the holding seedling block are: length $k$ is $25 \mathrm{~mm}$, width $i$ is $20 \mathrm{~mm}$, height $j$ is $10 \mathrm{~mm}$.

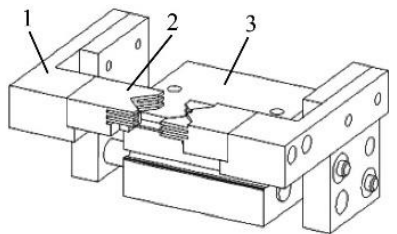

a. Holding seedling unit

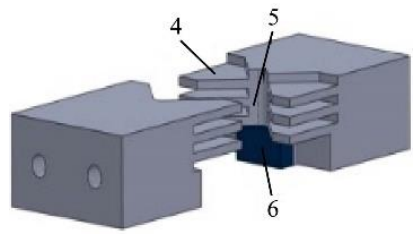

b. Holding seedling block
1. Clamping fingers 2. Holding seedling block 3. Cylinder 4. V-shaped holding seedling opening 5 . Holding seedling center 6 . Clamping pad

Figure 3 Structure of holding seedling unit

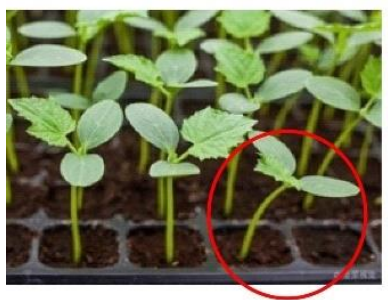

a. Seedling stem bending

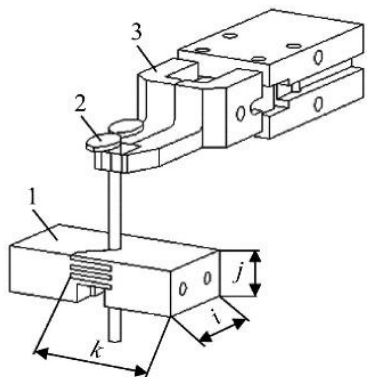

b. Holding seedling operation
1. Holding seedling block 2. Scion seedling 3. Clamping hand

Figure 4 Schematic of holding scion seedlings

After the seedlings are transported from the seedling loading station to the cutting position by the clamping hand, the moving unit of the cutting mechanism moves the V-shaped holding seedling block to the position directly below the clamping hand. At this time, the center of clamping hand clamping seedling coincides with the center of holding seedling mouth of V-shaped seedling holding block. Through the way of cross-holding of V-shaped holding blocks, the seedlings move along the V-shaped holding mouth into the center of holding seedlings, so that the scion seedling stems are in a vertical state.

\subsubsection{Design of cutting unit}

The cutting unit consists of a cutting cylinder, a cutter holder, a slide block, a cutter and a fixed plate, as shown in Figure 5. The cutter is installed at the front end of the cutter holder, and the cutter holder is installed on the fixed plate through the cooperation of the slide block and has thread connection with the piston rod of the cutting cylinder, and the cutting cylinder is installed on the fixed plate. The cutting cylinder drives the cutter to move linearly to complete the cutting operation of the scion seedling stem. The slide block can ensure the stability and accuracy of the cutter action.

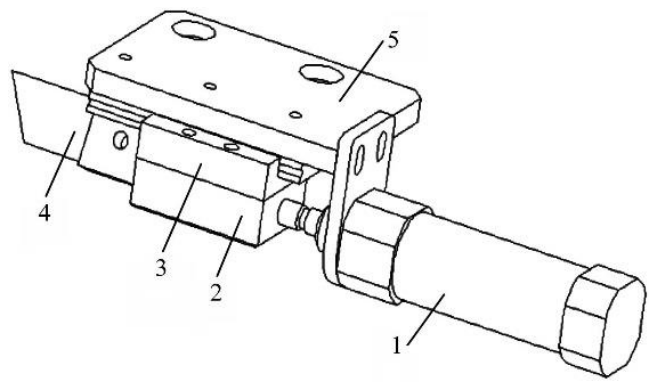

1. Cutting cylinder 2. Cutter base 3. Slider 4. Cutter 5. Fixing plate

Figure 5 Structure diagram of cutting unit

\subsection{Parameters of scion seedlings}

The scion seedlings were selected from cucumber seedlings and watermelon seedlings grafted with Cucurbita moschata, and seedlings were raised using a standard hole tray with $128(16 \times 8)$ holes. The hole tray was filled with peat, vermiculite and perlite, which were evenly mixed in the proportion of 1:1:1. After watering, the germinated seeds were planted into the hole tray covered with a layer of the substrate and then cultivated in a greenhouse at the temperature of $28^{\circ} \mathrm{C}-30^{\circ} \mathrm{C}$ for $7-10 \mathrm{~d}$. After growing to two cotyledons flattened, two true leaves appeared, which met the requirements of the standard seedlings for mechanical grafting. The structural parameters of scion seedlings are shown in Figure 6.

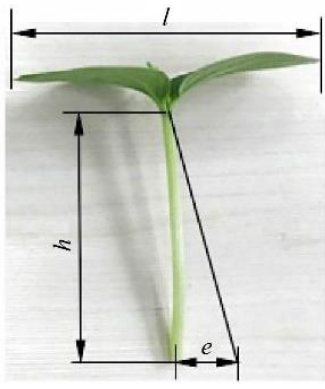

a. Main view

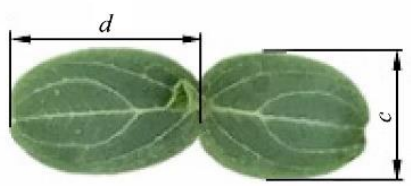

b. Top view
Note: $h$ is seedling height, $\mathrm{mm} ; l$ is cotyledon span, $\mathrm{mm} ; c$ is cotyledon width, $\mathrm{mm} ; d$ is cotyledon length, $\mathrm{mm} ; e$ is seedling stem bending, $\mathrm{mm}$.

Figure 6 External geometric parameters of scion seedlings

Due to the irregular cross-section shape of the scion seedling stem, the short axis $a$ and the long axis $b$ of the cross-section of the seedling stem need to be measured. The short axis $a$ is defined as the seedling stem in the cotyledon expansion direction, and the long axis $b$ is defined as the seedling stem perpendicular to the cotyledon expansion direction. The clamping direction of the stem of the scion seedlings by the clamping hand is the long axis, and the direction of the seedlings gathering of the holding seedling block is the short axis. The curvature of the scion seedling stem is the main basis for the design of holding seedling block, which provides a reference for determining the operating method of holding seedling block and the operating range of $\mathrm{V}$-shaped holding seedling mouth. When designing the cutting unit, it is necessary to understand the compression and shear characteristics of scion seedlings, so as to provide prerequisites for achieving flexible seedlings gathering and precise cutting. The test results of geometric parameters and mechanical properties of scion seedlings are shown in Table 1. The test results show that the short axis of the scion seedlings has better compression resistance than the long axis. In order to ensure the safety of clamping the seedlings, the parameters of clamping hand and holding seedling mouth were designed based on the long axis yield pressure. 
Table 1 Measurement results of geometric parameters and mechanical properties of scion seedlings

\begin{tabular}{|c|c|c|c|c|c|c|c|c|c|}
\hline Breeds & $\begin{array}{c}\text { Plant height } \\
h / \mathrm{mm}\end{array}$ & $\begin{array}{l}\text { Cotyledon } \\
\text { width } c / \mathrm{mm}\end{array}$ & $\begin{array}{c}\text { Cotyledon } \\
\text { length } d / \mathrm{mm}\end{array}$ & $\begin{array}{l}\text { Cotyledon } \\
\text { Span } l / \mathrm{mm}\end{array}$ & $\begin{array}{l}\text { Stem bending } \\
e / \mathrm{mm}\end{array}$ & $\begin{array}{c}\text { Long-axis stem } \\
b / \mathrm{mm}\end{array}$ & $\begin{array}{c}\text { Short-axis stem } \\
a / \mathrm{mm}\end{array}$ & $\begin{array}{l}\text { Yield pressure of } \\
\text { long-axis stem/N }\end{array}$ & $\begin{array}{c}\text { Maximum } \\
\text { shear force/N }\end{array}$ \\
\hline Cucumber & $52.35 \pm 3.82$ & $20.21 \pm 1.51$ & $25.41 \pm 1.63$ & $45.82 \pm 1.42$ & $4.35 \pm 0.68$ & $2.25 \pm 0.18$ & $2.02 \pm 0.15$ & $5.21 \pm 0.91$ & 1.246 \\
\hline
\end{tabular}

Note: \pm means standard deviation; the incubation time was $10 \mathrm{~d}$; the number of samples is 50 .

\subsection{Determination parameters of holding seedling block}

The design of holding seedling block needs to determine the method, structure shape and size of holding seedling block, and the opening angle of the V-shaped holding seedling mouth. During the holding seedling process, the gravity of the scion seedling is borne by the clamping hand, and the stem of the scion seedling moves rapidly along the contact surface towards the center of holding seedling under the thrust and friction on the contact surface of the V-shaped holding seedling mouth. The stress of the scion is shown in Figure 7.

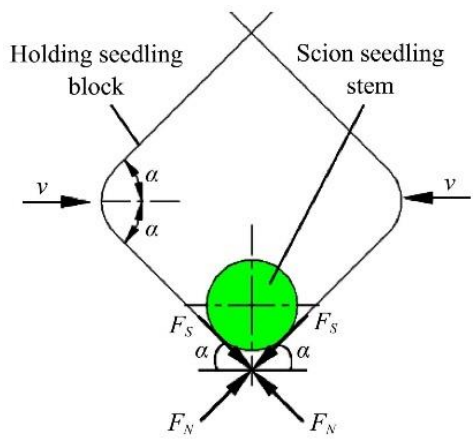

Note: $F_{N}$ is the supporting force of the holding seedling opening on the scion seedling, $\mathrm{N} ; F_{S}$ is the friction force of holding seedling slope on scion seedling, $\mathrm{N} ; \alpha$ is half of the flare angle of $\mathrm{V}$-shaped holding seedling opening, $\left({ }^{\circ}\right) ; v$ is the movement speed of holding seedling block, $\mathrm{m} / \mathrm{s}$.

Figure 7 Analysis of forces in holding scion seedlings process

It can be seen from Figure 7 that during the closing of the holding seedling block, the scion seedling must slide along the surface of the V-shaped holding seedling mouth in order to be centered. The comprehensive effect is to make the scion move towards the center of the holding seedling in the vertical direction, which meets the conditions of motion mechanics as:

$$
2 F_{N} \cos \alpha \geq 2 F_{S} \sin \alpha
$$

Due to

$$
F_{S}=\mu F_{N}
$$

where, $\mu$ is the maximum static friction coefficient between the scion seedling and the V-shaped holding seedling mouth, which can be obtained from Equations (1) and (2) as follows:

$$
\alpha \leq \arctan \frac{1}{\mu}
$$

Due to the complex structure of the holding seedling block and the difficulty of machining, it is easier to process with a 3D printer. The future resin 8000 (Shenzhen future workshop Technology Co., Ltd, Address: No.1 Yabao Road, Longgang District, Shenzhen, Guangdong Province, China) is was used as the printing material. The friction coefficient $\mu$ between the scion seedling and the holding seedling block was measured to be $0.658^{[34]}$.

Substituting $\mu$ into Equation (3), we can get

$$
\alpha \leq 56.65^{\circ}
$$

Thus

$$
2 \alpha \leq 113.3^{\circ}
$$

The smaller the opening angle of the $\mathrm{V}$-shaped holding seedling mouth, the easier it is to make the stem of scion seedling move towards the center of the holding seedling mouth. However, if the opening angle is too small, the moving travel of the holding seedling block will be larger. Considering the rationality of the structural design and the convenience of processing, the opening angle of the V-shaped holding seedling mouth was chosen to be $90^{\circ}$. The diameter of the center of the holding seedling block is closely related to the diameter of the scion seedlings, and the stress direction of the scion holding seedling is the short axis of the seedling stem. The thickness of each layer of the designed seedlings is $1 \mathrm{~mm}$, and the left and right holding seedling blocks are alternately distributed with 3 layers of concave and convex structures. The thickness of the V-shaped holding seedling mouth is $6 \mathrm{~mm}$, and the height of the clamping pad is designed to be $4 \mathrm{~mm}$. Therefore, the total height of the holding seedling block $j$ is $10 \mathrm{~mm}$.

According to the measurement results in Table 1, the short axis stem and the bending degree of the seedling stem of 50 cucumber seedlings were measured. The measurement results of Cucumber are as follows: the short axis stem $a$ is $(2.02 \pm 0.15) \mathrm{mm}$, and the seedling stem curvature is $(4.35 \pm 0.68) \mathrm{mm}$. Through the analysis of V-shaped holding seedling block structure, the diameter of holding seedling mouth is larger than that of seedling short-axis stem, and the width of holding seedling mouth is greater than that of seedling stem curvature, which can ensure that the seedling stem can enter the center of holding seedling mouth smoothly to complete the straightening operation. By setting the diameter and width of holding seedling mouth to $2.5 \mathrm{~mm}$ and $20 \mathrm{~mm}$, respectively, the precise matching between standard seedling and $\mathrm{V}$-shaped seedling blocks can be realized.

\subsection{Analysis parameters of cutting unit}

\subsubsection{Geometric model of cutting scion}

By establishing the geometry model of scion seedling cutting, the technical requirements of cutting operation for scion seedling and cutter were analyzed, as shown in Figure 8. It is necessary to determine the cutting height of the scion seedling $h_{1}$, the width of the cutter $l_{A B}$, and the height of the scion plant $h$. The cutting height $h_{1}$ is the length from the base of the cotyledon to the point $b$ of the upper part of the cutting.

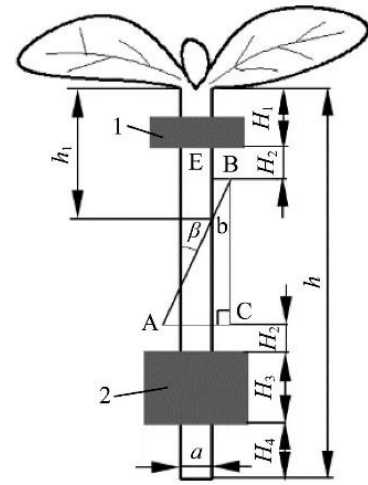

1. Clamping hand 2. Holding seedling block

Note: $h_{1}$ is the cutting height of scion seedling, $\mathrm{mm} ; h$ is the height of the scion plant, $\mathrm{mm} ; H_{1}$ is the clamping height of the seedling stem, $\mathrm{mm} ; H_{2}$ is the installation distance between cutting knife and clamping hand or holding seedling block, mm; $H_{3}$ is the height of holding seedling block, mm; $H_{4}$ is the length of seedling stem at the lower part of holding seedling block, mm; $a$ is the short axis of the scion, $\mathrm{mm} ; l_{B E}$ is the distance between the cutter and seedling stem, $\mathrm{mm} ; \beta$ is the cutting angle of the scion, $\left({ }^{\circ}\right)$.

Figure 8 Geometric model of cutting scion 
According to the analysis in Figure 8, the cutting height of the scion seedling

$$
h_{1}=H_{1}+H_{2}+l_{B E} \tan \beta
$$

The width of the cutter

$$
l_{A B}=\frac{a+2 l_{B E}}{\sin \beta}
$$

The height of the scion plant

$$
\left\{\begin{array}{l}
h=H_{1}+2 H_{2}+l_{B C}+H_{3}+H_{4} \\
l_{B C}=\frac{a+2 l_{B E}}{\tan \beta}
\end{array}\right.
$$

Solving Equation (8), we can get

$$
h=H_{1}+2 H_{2}+H_{3}+H_{4}+\frac{a+2 l_{B E}}{\tan \beta}
$$

The data of $H_{1}, H_{2}, H_{3}, H_{4}$ and $l_{B E}$ are all theoretical design values. When the thickness of the gripper is $4 \mathrm{~mm}, H_{1}$ is taken as $6 \mathrm{~mm}$. This indicates that the distance from the upper part of the gripper to the base of the cotyledon is $2 \mathrm{~mm}$, which can ensure the safe clamping of seedling stem at the lower part of the cotyledon. When $\mathrm{H}_{2}$ is $2 \mathrm{~mm}$, the cutter can enter between the clamping hand and the holding block smoothly. $H_{3}$ is $10 \mathrm{~mm}$. When $H_{4}$ is taken as $10 \mathrm{~mm}$, it can ensure that the stem slides smoothly to the holding seedling center along with the $\mathrm{V}$-shaped holding opening during the closure process of the holding block. When $l_{B E}$ is 2 $\mathrm{mm}$, the scion seedling stem can be completely cut off by the cutter.

It can be known from Table 1 that the short axis of cucumber seedlings is slightly larger than that of watermelon seedlings. Therefore, cucumber seedlings were selected as the object. The long axis of the seedling stem $a=2.02 \mathrm{~mm}$, and the cutting angle $\beta$ is $20^{\circ[34]}$. By substituting the above parameters into Equations (6), (7), and (9), we can get, $h_{1}=10.92 \mathrm{~mm}, l_{A B}=13.33 \mathrm{~mm}$, and $h=$ $42.52 \mathrm{~mm}$. For grafting, the cutting height of scion seedlings should be $10-15 \mathrm{~mm}$. The average measured plant heights of cucumber and watermelon are $52.35 \mathrm{~mm}$ and $50.86 \mathrm{~mm}$, respectively. The width of the cutter $l_{\mathrm{AB}}$ is rounded to $14 \mathrm{~mm}$. All parameters meet the technical requirements of cutting scion.

\subsubsection{Determination parameters of cutting operation}

The inclination angle of the cutter $\gamma$ refers to the angle between the cutting edge and the vertical direction. The larger the inclination angle of the cutter, the smaller the cutting resistance is, the more favorable the cutting is, but the larger the cutting travel is. A geometric model of the scion cutting process is established, as shown in Figure 9.

According to the analysis in Figure 9, the cutting stroke of the cutter

$$
\left\{\begin{array}{l}
Y=l_{A P} \sin \gamma+L+b+\delta \\
l_{A P}=\frac{l_{A B}}{\cos \gamma}
\end{array}\right.
$$

Solving Equation (10), we can get

$$
Y=l_{A B} \tan \gamma+L+b+\delta
$$

Taking watermelon seedling as the object $(b=2.56 \mathrm{~mm})$, take $L=8 \mathrm{~mm}, \delta=2 \mathrm{~mm}$, and $l_{\mathrm{AB}}=14 \mathrm{~mm}$, which can meet the operating conditions that the scion is completely cut off. Substituting into Equation (10), we can get

$$
Y=14 \tan \gamma+12.56
$$

When the angle of the inclination of cutter $\gamma=40^{\circ}$, the cutting success rate is the highest ${ }^{[35]}$. Substituting it into Equation (12), the cutting stroke $Y$ of the cutter is $24.31 \mathrm{~mm}$, rounded to $25 \mathrm{~mm}$.
Therefore, the SMC CDJ2B10-25-B cylinder (SMC (China) Co., Ltd, Address: A2, XingSheng Street, Beijing, China) was selected as the model of cutting cylinder, to meet the structural design and operation requirements of the cutting mechanism. Cutting speed is the important parameter of cutting seedling operation. The cutter of the cutting mechanism is driven by an air cylinder. When the air pressure is $0.3 \mathrm{MPa}$, the linear speed will reach $0.15 \mathrm{~m} / \mathrm{s}$, which is 100 times higher than the downward speed of the cutter $(1.5 \mathrm{~mm} / \mathrm{s})$ in the seedling cutting test, fully meeting the cutting conditions of the seedling stem. Therefore, the cutting speed has no effect on the cutting model.

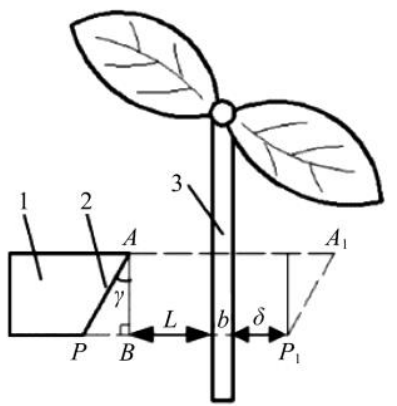

1. Cutter 2. Cutting edge 3. Scion seedling

Note: $l_{\mathrm{AP}}$ is the length of cutting edge, $\mathrm{mm} ; l_{\mathrm{AB}}$ is the width of the cutter, $\mathrm{mm} ; b$ is the long axis of the scion, $\mathrm{mm} ; L$ is the distance between the cutting edge and seedling stem before cutting, $\mathrm{mm} ; \delta$ is the distance between cutting edge and seedling stem after cutting, $\mathrm{mm} ; \gamma$ is the inclination angle of cutting edge, $\left({ }^{\circ}\right)$.

Figure 9 Geometric model of cutting scion stem process

\subsection{Test of holding and cutting scion}

In order to verify the rationality and cutting performance of the cutting mechanism design, the success rate $m$ and damage rate $n$ of the holding seedling, the cutting success rate $q$ and the cutting accuracy rate $p$ were used as evaluation indexes ${ }^{[34]}$. The successful holding seedling actually means that the stems of the seedlings are straightened and undamaged after the closure of V-shaped seedling blocks. The successful cutting refers to the situation that the cutter cuts off the seedling stem and the cutting surface is smoothly flat without fracture. Among them:

$$
\begin{gathered}
n=\frac{N}{F} \times 100 \% \\
n=\frac{M}{F} \times 100 \% \\
q=\frac{E}{T} \times 100 \% \\
p=1-\frac{\left|\beta_{0}-\beta_{1}\right|}{\beta_{0}} \times 100 \%
\end{gathered}
$$

where, $N$ is the number of successful scion holding seedling; $M$ is the number of scion holding seedling damaged; $E$ is the number of successful scion seedling cutting; $F$ is the total number of scion holding seedling tested; $T$ is the total number of scion seedling cutting tested; $\beta_{0}$ is the target cutting angle, $\left({ }^{\circ}\right) ; \beta_{1}$ is the actual cutting angle, $\left({ }^{\circ}\right)$.

Two groups of 60 cucumber seedlings were selected to carry out a comparative test of holding seedling with the common arc clamp and V-shaped holding seedling block. The arc-shaped clamping mouth is an integral structure, with a diameter of $2.5 \mathrm{~mm}$ and a thickness of $10 \mathrm{~mm}$, as shown in Figure 10a. The diameter of the center of the $\mathrm{V}$-shaped holding seedling block is $2.5 \mathrm{~mm}$, the thickness is $10 \mathrm{~mm}$, and the width of the V-shaped mouth $f$ is $20 \mathrm{~mm}$ and the opening angle of holding seedling is $90^{\circ}$, as shown in Figure 10b. The test process was as follows: at first, the scion seedlings were put into the seedling feeding platform, carried to the 
cutting station by the clamping hand, and gathered in the holding seedling block of the scion cutting mechanism, next, the clamping hand and the holding seedling block was reset to remove the scion seedlings, at last, the success rate and injury rate of the holding seedling of the scion was analyzed statistically.

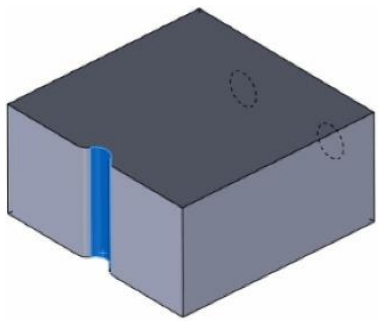

a. Arc-shaped clamp

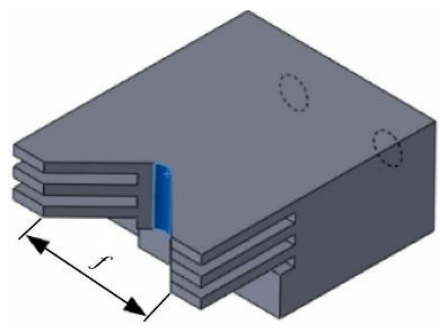

b. V-shaped holding seedling block
Note: $\mathrm{f}$ is the width of the V-shaped mouth

Figure 10 Structure diagram of arc-shaped clamp and V-shaped holding seedling block

Three groups of 50 cucumber seedlings were selected. The thickness of the cutter is $0.2 \mathrm{~mm}$, the angle of the cutter is $40^{\circ}$, the cutting cylinder pressure is $0.3 \mathrm{MPa}$, and the target cutting angle is $20^{\circ}$. After the scion cutting operation is completed, remove the scion seedlings, use a vernier caliper to measure the cutting length and the short axis length, calculate the actual cutting angle, and analyze the accuracy and success rate of scion cutting statistically.

The cutting scion test process was as follows: Firstly, the scion seedlings were placed into the seedling feeding platform, and carried to the cutting station by the clamping hand. Then the moving unit cylinder was extended to drive the holding seedling unit and the cutting unit to move to the holding seedling position; the holding seedling block was closed to carry out the holding seedling, centering and clamping fixation for the scion seedling stem; next, the cutting cylinder was extended to drive the cutter to move and cut off the scion seedling stem. Finally, each unit was reset to complete the holding and cutting seedling operations. The test device is shown in Figure 11.

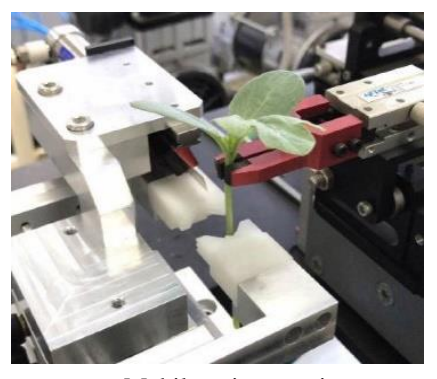

a. Mobile unit extension

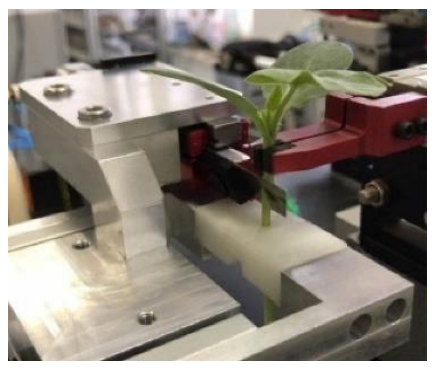

c. Cutting seedling stem

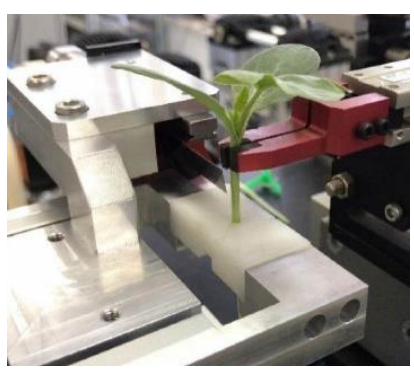

b. Holding seedling

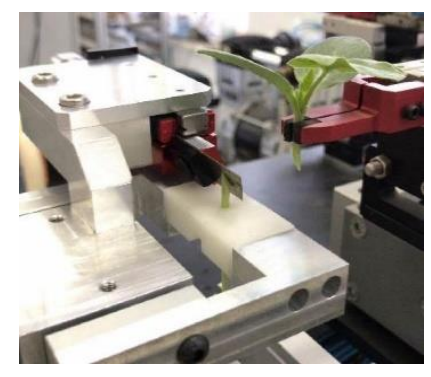

d. All units reset
Figure 11 Test device of cutting scion

\section{Results and discussion}

The test results of scion holding seedlings are shown in Table 2. It can be known from the test that the success rate of the
V-shaped holding seedling block is $98.33 \%$, which is $13.33 \%$ higher than the arc-shaped clamp; the injury rate is only $1.67 \%$, meeting the design requirements. The holding seedling unit can improve the success rate of holding seedlings, mainly because the V-shaped holding seedling block guides the holding seedling, which corrects the curved shape of the scion seedling stem, and improves the adaptability of the cutting mechanism to the scion. Even if there is crush damage in the mouth of the holding seedling of the seedling stem, the position of the holding seedling of the seedling stem will be cut off without affecting the cutting quality of the scion. However, the curved clamp cannot accurately clamp the curved stem of scion seedling, and the seedlings that do not enter the curved clamp will be squeezed and damaged.

Table 2 Test results of holding scion seedlings

\begin{tabular}{cccc}
\hline Groups & $\begin{array}{c}\text { Samples } \\
\text { number }\end{array}$ & $\begin{array}{c}\text { Success rate of holding } \\
\text { seedling } m / \%\end{array}$ & $\begin{array}{c}\text { Injury rate of } \\
\text { seedling } n / \%\end{array}$ \\
\hline $\begin{array}{c}\text { Curved clamping hand } \\
\text { V-shaped holding } \\
\text { seedling block }\end{array}$ & 60 & 85 & 15 \\
\hline
\end{tabular}

The test results of scion cutting are shown in Table 3. It can be known from the test that the cutting accuracy of the cutting mechanism is $97.75 \%$, and the cutting accuracy depends on the effect of the holding seedling. The better the stem correctness of the seedlings after the holding seedling, the higher the cutting accuracy is. The cutting success rate is $98.67 \%$, the cutting angle is $19.55^{\circ}$, and the cutting length is $6.31 \mathrm{~mm}$, which meet the requirements of mechanical grafting. The upper and lower two-point positioning of the stem of the scion seedling are formed by clamping hand and the holding seedling block, which improves the cutting success rate of the scion seedling.

Table 3 Test results of cutting scion

\begin{tabular}{cccccc}
\hline Groups & $\begin{array}{c}\text { Short-axis stem } \\
\text { of scion } \\
b / \mathrm{mm}\end{array}$ & $\begin{array}{c}\text { Actual cutting } \\
\text { angle } \\
\beta /\left(^{\circ}\right)\end{array}$ & $\begin{array}{c}\text { Section } \\
\text { length } \\
L / \mathrm{mm}\end{array}$ & $\begin{array}{c}\text { Cutting } \\
\text { accuracy } \\
\text { rate } p / \%\end{array}$ & $\begin{array}{c}\text { Cutting } \\
\text { success rate } \\
q / \%\end{array}$ \\
\hline 1 & 2.08 & 19.42 & 6.26 & 97.10 & 98 \\
2 & 2.10 & 19.57 & 6.27 & 97.85 & 98 \\
3 & 2.15 & 19.66 & 6.39 & 98.30 & 100 \\
Average & 2.11 & 19.55 & 6.31 & 97.75 & 98.67 \\
\hline
\end{tabular}

Through the design of V-shaped seedling block to straighten the scion seedling stem, the upper and lower points of scion seedling stem can be fixed, which can not only improve the scion cutting success rate and cutting quality but also solve the influence of scion stem bending on cutting quality. The seedling section formed by the existing rotary cutting mechanism is an arc-shaped surface, which makes the grafted seedling section not fit tightly, thus affecting the survival of the grafted seedling; the seedling section formed by the linear cutting mechanism designed in this paper is a plane design, which can improve the tightness of the grafting seedling section and is conducive to the survival of the grafting seedling.

\section{Conclusions}

In order to improve the adaptability and cutting accuracy of the grafting robot to the morphological changes of scion seedling stem, a scion cutting mechanism with the function of holding seedling and positioning was designed, the operating parameters of the mechanism were analyzed and optimized, and the test of holding seedling and cutting performance was carried out. The following conclusions were drawn. 
(1) The holding seedling unit consists of the clamping finger, the holding seedling block and the air cylinder. The holding seedling block adopts a V-shaped multilayer concave and convex structure and a cross-closed holding seedling operation mode. The V-shaped holding seedling mouth has a better guiding and centering effect on the scion seedling stem, which improves the adaptability of the cutting mechanism to the growth morphology of the scion.

(2) Based on the determination of the basic parameters of scion seedlings, the opening angle of the V-shaped holding seedling mouth of the holding seedling block was designed to be $90^{\circ}$, and the thickness of the single-layer was $1 \mathrm{~mm}$. The thickness of the holding seedling block can be adjusted by increasing or decreasing the number of layers of the V-shaped holding seedling mouth. The concave and convex structure of the left and right holding seedling block has 3 layers ( $6 \mathrm{~mm}$ thick), respectively, and the height of the clamping pad is $4 \mathrm{~mm}$. Therefore, the total thickness of the holding seedling block is $10 \mathrm{~mm}$.

(3) The linear cutting unit was designed, and a geometric model for scion cutting and cutter operation was established. The cutting height of the scion is $10.92 \mathrm{~mm}$, the width of the cutter is $14 \mathrm{~mm}$, the height of the scion plant is $42.52 \mathrm{~mm}$, the angle of the cutter is $40^{\circ}$, and the travel is $25 \mathrm{~mm}$, which meet the requirements of mechanical grafting cutting operation.

(4) The test results show that the success rate of holding the seedling of the V-shaped holding block reaches $98.33 \%$, which is increased by $13.33 \%$ compared with the arc-shaped clamp, and the seedling injury rate is only $1.67 \%$. The V-shaped holding seedling block corrected the curved shape of the stem of the scion seedling and the guiding and centering effect are obvious. The accuracy of cutting scion is $97.75 \%$, and the cutting success rate is $98.67 \%$. The cutting accuracy depends on the effect of the holding seedling. Using the clamping hand and the holding seedling block to position the upper and lower two-point of the stem of the scion seedling can effectively assist the cutting operation and improve the cutting accuracy.

\section{Acknowledgements}

This work was financially supported by the Beijing Academy of Agriculture and Forestry Sciences Innovation Ability Project (Grant No. KJCX20180422), the Key Research and Development projects in Ningxia Hui Autonomous Region (Grant No. 2018BBF02024), and the National Key Technology Research and Development Program of China (Grant No. 2013AA102406). The authors acknowledge their generous financial assistance.

\section{[References]}

[1] Sun G W, Chen R Y, Liu H C. Causes and control measures for continuous cropping obstacles in protected vegetable cultivation. Transactions of the CSAE, 2005; 21(14): 184-188. (in Chinese)

[2] Jiang W J, Deng J, Yu H J. Development situation, problems and suggestions on industrial development of protected horticulture. Scientia Agricultural Sonica, 2015; 48 (17): 3515-3523. (in Chinese)

[3] Yang W J, Huang Y, Bie Z L. Grafting techniques of Solanaceae vegetables. Journal of Changjiang Vegetables, 2019; 22: 23-28. (in Chinese)

[4] Qi F, Wei X M, Zhang Y F. Development status and future research emphases on greenhouse horticultural equipment and its relative technology in China. Transactions of the CSAE, 2017; 33(24): 1-9. (in Chinese)

[5] Huang Y, Kong Q S, Chen F, Bie Z L. The history, current status and future prospects of vegetable grafting in China. Acta Horticulturae, 2015;
1086: 31-39.

[6] Zhang K L, Chu J, Zhang T Z, Yin Q, Kong Y S, Liu Z. Development status and analysis of automatic grafting technology for vegetables. Transactions of the CSAM, 2017; 48(3): 1-13. (in Chinese)

[7] Lou J Z, Li J P, Zhu P A, Lyu G L, Wang M. Optimization of suction head of scion clamping mechanism for vegetable grafting machine. Transactions of the CSAM, 2013; 44(2): 63-68. (in Chinese)

[8] Jiang F, Xie Z J, Zhang G D, Wang C, Gu S. Design and experiment of precutting device of plug tray rootstock seedlings. Journal of Agricultural Mechanization Research, 2020; 42(4): 188-191. (in Chinese)

[9] Jiang K, Zheng W G, Zhang Q, Guo R. Development and experiment of vegetable grafting robot. Transactions of the CSAE, 2012; 28(4): 8-14. (in Chinese)

[10] Chu Jia, Zhang L B, Zhang T Z, Zhang W B, Wang L J, Liu Z. Design and experiment of grafting robot operated by one person for cucurbitaceous seedlings cultivated in plug trays. Transactions of the CSAM, 2017; 48(1): 7-13.(in Chinese)

[11] Tong J H, Ding Y H, Wu C Y, Yu Q C, Pan J H, Sun L. Design and experiment of key mechanism for semi-automatic vegetable grafting machine. Transactions of the CSAM, 2018; 49(10): 65-72. (in Chinese)

[12] Xie Z J, Gu S, Chu Q, Li B, Fan K J, Yang Y L, et al. Development of a high-productivity grafting robot for Solanaceae. Int J Agric \& Biol Eng, 2020; 13(1): 82-90.

[13] Ito T. Present state of transplant production practices in Japanese horticultural industry. Transpl. Prod. Syst., 2011; 85: 65-82.

[14] Kobayashi K, Sasaya S. Study on automation of seedlings feeding for grafting robot for cucurbitaceous vegetables (Part2)-Examination of a cotyledon-orienting mechanism for stock. Journal of the Japanese Society of Agricultural Machinery and Food Engineers, 2007; 69(5): 70-77.

[15] Kurata K. Cultivation of grafted vegetables. II. Development of grafting robots in Japan. HortScience, 1994; 29(4): 240-244.

[16] Kim H M, Hwang S J. Comparison of pepper grafting efficiency by grafting robot. Protected Horticulture and Plant Factory, 2015; 24(2): 57-62.

[17] Kubota C, Mcclure M A, Kokalis-Burelle N, Bausher M G, Rosskopf E N Vegetable grafting: history, use, and current technology status in North America. HortScience: a publication of the American Society for Horticultural Science, 2008; 43(6): 1664-1669.

[18] Lee J, Kubota C, Tsao S J, Bie Z, Hoyos Echevarria P, Morra L, et al. Current status of vegetable grafting diffusion, grafting techniques, automation. Scientia Horticulture, 2010; 127(2): 93-105.

[19] Pekkeriet E J, Van Henten E J. Current developments of high-tech robotic and mechatronic systems in horticulture and challenges for the future. Acta Horticulturae, 2011; 893: 85-94.

[20] Atlantic Man. Group of manufacturers. Semi-automatic universal grafting robot 'GR 300'. Patented No. EP2599380A1. http://tech.atlanticgroup.it/equipment/gr300/ Accessed on [2020-08-10].

[21] Comba L, Gay P, Ricauda Aimonino D. Robot ensembles for grafting herbaceous crops. Biosyst. Eng., 2016; 146: 227-239.

[22] Conic System. www.conic-system.com. Accessed on [2020-08-10].

[23] Chen S, Chiu Y C, Chang Y C. Development of a tubing-grafting robotic system for fruit-bearing vegetable seedlings. Appl. Eng. Agric., 2013; 26(4): 707-714.

[24] Kobayashi K, Fujii M, Ohkoshi T. Development of automatic seedling feeding mechanism for grafting robot for cucurbits. Journal of the Japanese Society of Agricultural Machinery, 2011; 73(1): 57-64.

[25] Ohkoshi T, Kobayashi K. Development of automatic seedling feeding device for cucurbits grafting robot (Part1)-Evaluation of automatic stock feeder. Journal of the Japanese Society of Agricultural Machinery and Food Engineers, 2013; 75(2): 100-107.

[26] Kang D H, Lee S Y, Kim J K, Park M J, Son J K, Yun S W Development of an automatic grafting robot for fruit vegetables using image recognition. Protected Horticulture and Plant Factory, 2019; 28(4): 322-327.

[27] Chu J, Zhang T Z. Design and experiment of vegetable grafting robot operated by one-person for cucurbitaceous seedlings cultivated in humus pots. Transactions of the CSAM, 2014; 45(S1): 259-264. (in Chinese)

[28] Xu L M, Zhang T Z, Liu C Q. Study on robot system for auto grafting of vegetable-design of the rotary cutting mechanism. Journal of China Agricultural University, 2000; 5(2): 34-36. (in Chinese)

[29] ISO Group, Inc. ISO Grafting 1200. https://www.iso-group.nl. Accessed on [2020-08-10]. 
[30] Jiang K, Wang X, Zhang Q, Feng Q C. Design and experiment of grafting device for solanaceous vegetable. Journal of Agricultural Mechanization Research, 2015; 37(4): 131-135, 139. (in Chinese)

[31] Jiang K, Wang J W, Li C L. Design and test of melon grafting device based on splice grafting. International Agricultural Engineering Journal, 2018; 27(4): 65-74.

[32] Zhang J. Research on design and prototype building of a vision based grafting machine. Master dissertation. Hangzhou: Zhejiang Sci-Tach University, 2018; 67p. (in Chinese)
[33] He L Y, Cai L Y, Wu C Y. Vision-based parameters extraction of seedlings for grafting robot. Transactions of the CSAE, 2013; 29(24): 190-195. (in Chinese)

[34] Jiang K. Study on mechanism and experimental device of splice mechanical grafting of cucurbit. $\mathrm{PhD}$ dissertation. Harbin: Northeast Agricultural University, 2019; 132p. (in Chinese)

[35] Gu S, Li K, Chu Q, Yang Y L, Liu K, Zhong L X. Experiment of 2JX-M series vegetable cutting devices for grafting. Transactions of the CSAE, 2012; 28(10): 27-32. (in Chinese) 